\title{
ANALISIS KEANEKARAGAMAN JENIS MANGROVE DI KECAMATAN KUALA BARU, ACEH SINGKIL
}

\author{
Dina Firmadiana, Hairul Basri, Essy Harnelly* \\ Program Studi Kehutanan, Fakultas Pertanian, Universitas Syiah Kuala \\ Email: eharnelly@gmail.com
}

\begin{abstract}
Abstrak : Kawasan Suaka Margasatwa Rawa Singkil mempunyai fungsi di bidang konservasi yang sangat penting, karena kawasan ini memiliki tingkat keanekaragaman yang sangat tinggi. Saat ini, data untuk kandungan bahan organik dan analisis vegetasi di hutan mangrove Aceh Singkil belum begitu lengkap, karena itu dibutuhkannya penelitian ini yang juga dapat menjadi acuan dalam peningkatan rehabilitasi hutan mangrove kedepannya. Metode dalam penelitian ini yaitu menggunakan metode purposive sampling. Dalam penelitian ini diperoleh nilai indeks keanekaragaman jenis yaitu antara $0-0,35$, nilai ini tergolong dalam $\mathrm{H}^{\prime}$ $<2,3026$ yang berarti tingkat kestabilan komunitas yang rendah dan tingkat keanekaragamannya juga rendah. Rendahnya nilai indeks keanekaragaman disebabkan oleh kandungan bahan organik tanah yang rendah, yaitu kandungan C-organik, N-total, dan $\mathrm{pH}$ tanah.
\end{abstract}

Kata Kunci : Keanekaragaman, Bahan Organik, Hutan Mangrove

\begin{abstract}
The Singkil wildlife reserve has a very important conservation function, because this area has very high diversity. Currently, the data for organic matter content and analysis of vegetation in Aceh Singkil mangrove forests are not yet complete, this research is needed which can also be a reference in improving mangrove forest rehabilitation in the future. The method used in this research is purposive sampling method. Based on the research results, the index value of species diversity between $0-0,35$ is obtained, this value belong to $\mathrm{H}^{\prime}<2.3026$ which a low level of community stability and indicates a small level of diversity. The low diversity index value is caused by the low content of soil organic matter (C-organic, N-total, and soil $\mathrm{pH})$.
\end{abstract}

Keywords: Diversity, organic material, mangrove forest

\section{PENDAHULUAN}

Aceh Singkil berada pada $2^{\circ} 27^{\prime} 30^{\prime \prime}$ LU dan 9745'00” BT. Data Dinas Kehutanan dan Perkebunan Aceh Singkil pada tahun 2012 menyebutkan bahwa Aceh singkil memiliki kawasan ekosistem mangrove yang luasnya sebesar 6.514 Ha. Berdasarkan SK Menteri Kehutanan No. 166/Kpts-II/1998 kawasan Suaka Margasatwa Rawa Singkil ditetapkan pada tanggal 26 Februari 1998, dengan luas kawasan 102.500 Ha. Selain sebagai kawasan suaka margasatwa, Rawa Singkil juga ditetapkan sebagai bagian dari Kawasan Ekosistem Lauser berdasarkan Keppres No. 33 Tahun 1998. Saat ini kawasan hutan mangrove semakin berkurang luasnya akibat eksploitasi yang terjadi dan perubahan fungsi kawasan (Giri, et al., 2011).

Fungsi dan manfaat mangrove yang secara umum telah banyak dikenal menjadikan sumberdaya mangrove terancam, hal ini dikarenakan akses yang mudah juga nilai komponen biodiversitas yang tinggi (Valiela et al., 2001 \& Onrizal, 2005). Meskipun rehabilitasi mangrove juga dilakukan, namun penyebab kerusakan hutan mangrove terus terjadi dan mengalami peningkatan (Primavera, 2005 \& Dave, 2006). Hal itu menyebabkan potensi kehilangan hutan mangrove semakin cepat dibandingkan dengan kehilangan hutan tropis daratan dan terumbu karang (Duke, et al., 2007). Inilah penyebab menurunnya produktivitas ekosistem mangrove dan pesisir pantai yang menjadi salah satu pusat permasalahan lingkungan di dunia. 
Saat ini, data untuk kandungan bahan organik dan analisis vegetasi di hutan mangrove Aceh Singkil belum begitu lengkap, karena itu dibutuhkannya penelitian ini yang juga dapat menjadi acuan dalam peningkatan rehabilitasi hutan mangrove kedepannya.

\section{METODE PENELITIAN}

Penelitian ini dilaksanakan dari bulan 10 Agustus 2020 sampai 20 November di Desa Kuala Baru, Kawasan Hutan Mangrove Suaka Margasatwa Rawa Singkil, Aceh Singkil. Metode dalam penelitian ini yaitu menggunakan metode purposive sampling, yaitu metode yang dalam pengambilan sampel tidak mengikuti ketentuan tertentu dan pengambilan titik sampel sudah dipertimbangkan dengan baik oleh peneliti.

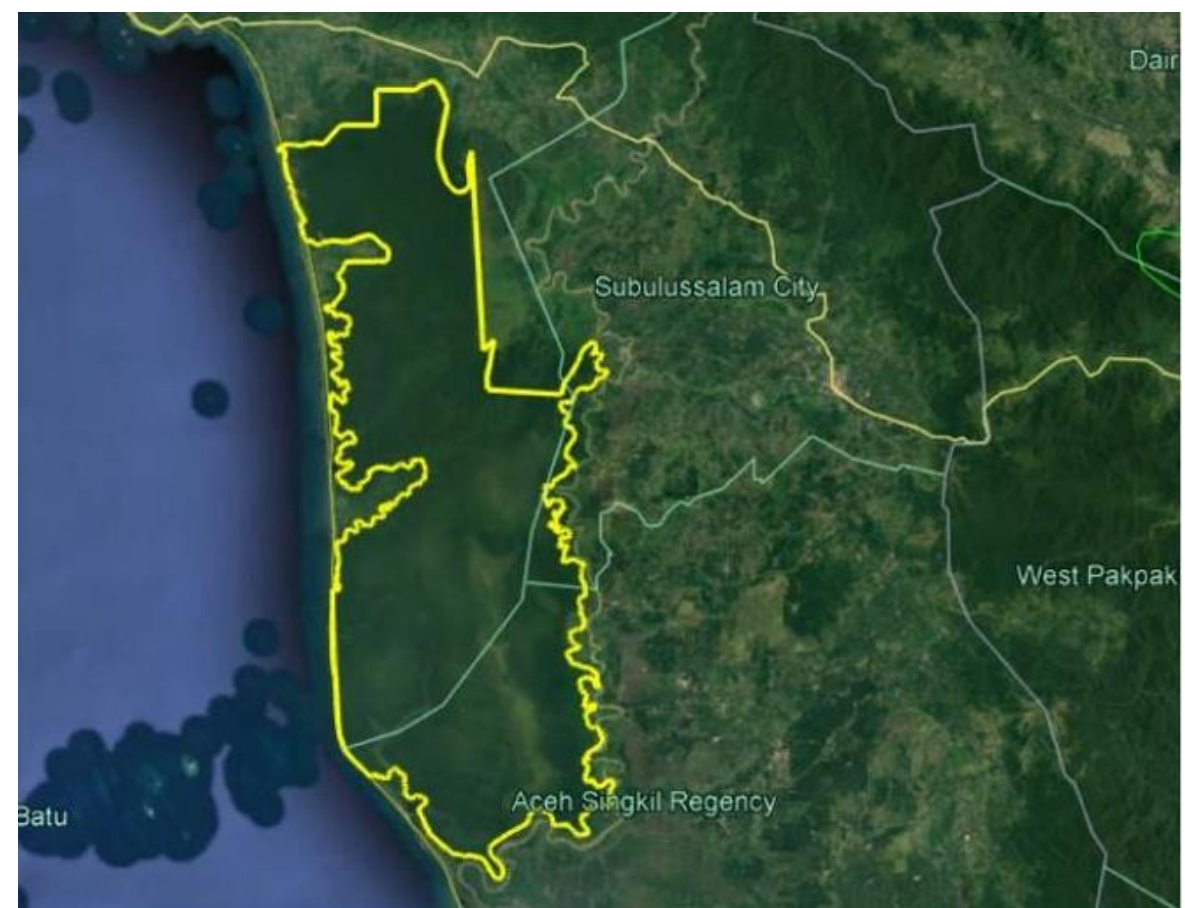

(Sumber : smart-tbk.com)

Gambar 1. Peta Kawasan Suaka Margasatwa Rawa Singkil

\section{Alat dan Objek Penelitian}

Adapun alat yang digunakan dalam penelitian ini yaitu GPS (untuk megambil titik koordinat), meteran ukuran 50m (untuk mengambil titik sampel), bor tanah (untuk mengambil sampel tanah), sendok tanah (untuk mengambil sampel tanah), haga hypsometer (untuk mengukur tinggi pohon), ph meter (untuk mengukur ph tanah), kamera (untuk mengambil dokumentasi gambar). Objek dalam penelitian ini adalah ekosistem hutan mangrove di Desa Kuala Baru Sungai, Kecamatan Kuala Baru, Kabupaten Aceh Singkil.

\section{Tahapan Penelitian}

Tahapan penelitian yang dilakukan dalam penelitian ini yaitu sebagai berikut : 
1. Tahap persiapan, yaitu dilakukan survey lokasi penelitian dan surat administrasi penelitian, juga persiapan alat dan bahan yang akan digunakan untuk pengambilan data di lapangan.

2. Pengambilan data kelas penggenangan dan frekuensi penggenangan, dalam hal ini dilakukan melalui wawancara dengan masyarakat sekitar.

3. Pengambilan data kandungan bahan organik tanah dilakukan dengan mengambil sampel tanah di setiap titik sampel data analisis vegetasi (Gambar 2).

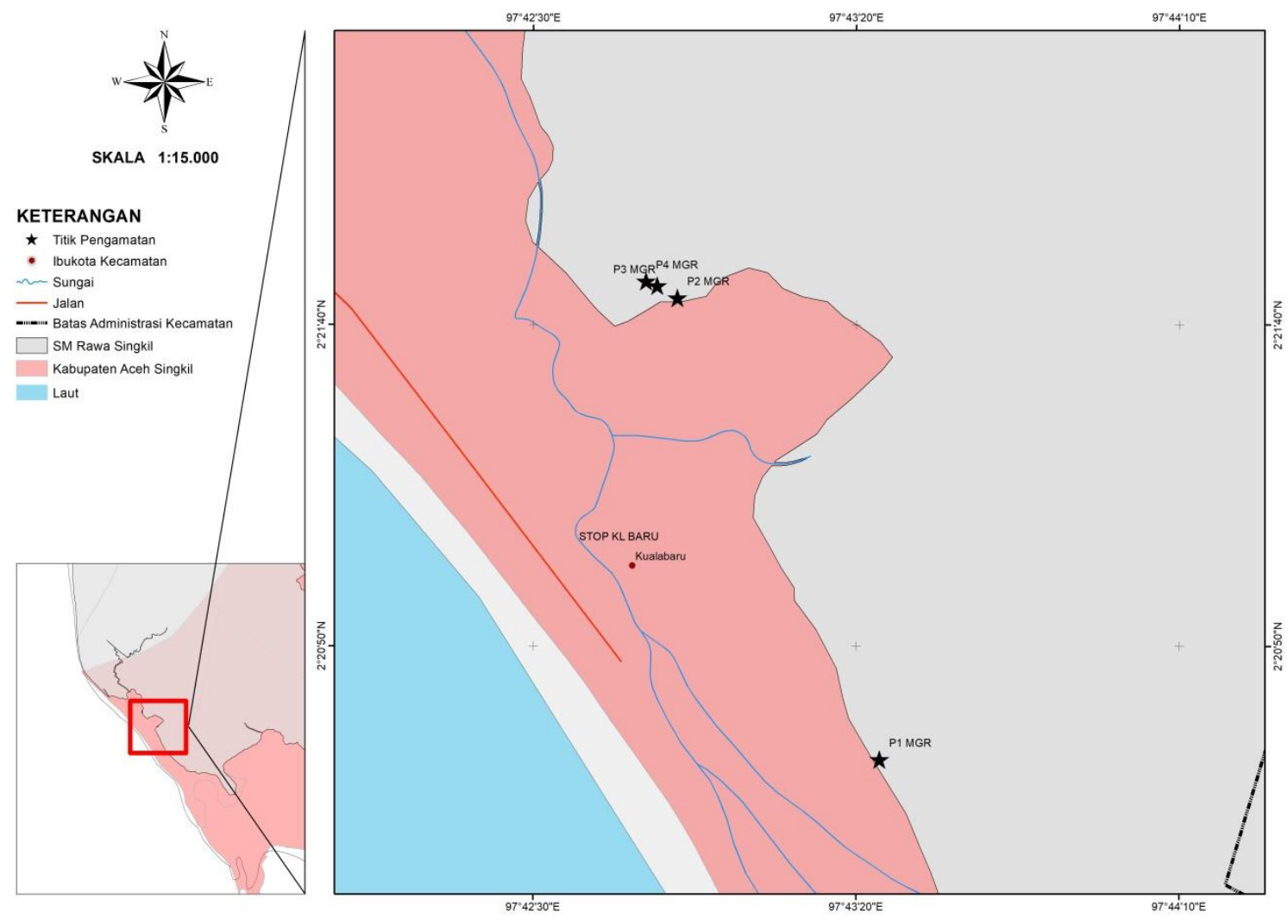

Gambar 2. Peta Titik Sampel Vegetasi dan Tanah

4. Pengambilan data analisis vegetasi dilakukan dengan mengambil 4 titik sampel, data ini diambil di seluruh kawasan dengan menggunakan metode kuadran lingkaran dengan ukuran jari-jari $=10 \mathrm{~m}$ dan dibuat lagi beberapa plot untuk subplot pengamatan dengan ukuran sebagai berikut (Gambar 4) :

a. Untuk tingkat semai dengan ukuran jari-jari $1 \mathrm{~m}$ yang kira-kira tingginya $<1,5$ meter.

b. Untuk tingkat pancang dengan ukuran jari-jari $2 \mathrm{~m}$ yang tingginya kira-kira $>1,5$ meter.

c. Untuk tingkat tiang dengan ukuran jari-jari $5 \mathrm{~m}$ yang memiliki diameter $10 \mathrm{~cm}-19$ $\mathrm{cm}$.

d. Untuk pohon dengan ukuran jari-jari $10 \mathrm{~m}$ yang memiliki diameter $>20 \mathrm{~cm}$. 


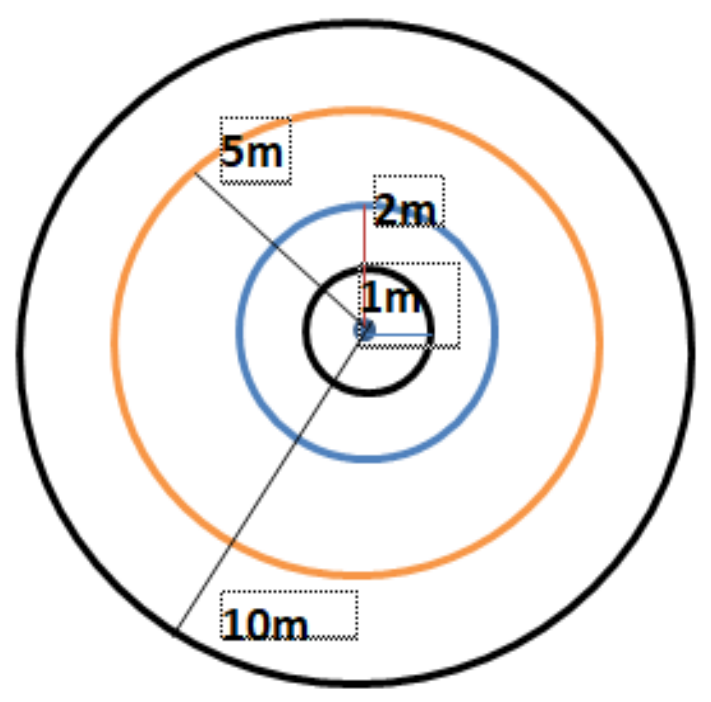

Gambar 1. Desain Plot Sampling

\section{Analisis Data}

Data yang akan dilakukan analisis yaitu sebagai berikut :

1. Analisis Data Tanah

Data sampel tanah yang sudah di ambil kemudian dilakukan analisis kandungan bahan organik seperti C-organik, Nitrogen (N-total), dan $\mathrm{pH}$ tanah. Analisis data tanah dilakukan di Laboratorium Kimia Tanah, Fakultas Pertanian Universitas Syiah Kuala.

2. Analisis Data Vegetasi

Data vegetasi yang didapat kemudian diolah untuk mendapatkan Indeks Nilai Penting (INP) dan Indeks Dominansi Jenis (C) dengan menggunakan rumus d bawah ini :

a. Indeks Nilai Penting (INP)

Indeks Nilai Penting $($ INP) $=$ KR + FR + DR

Kerapatan $(\mathrm{K})=\frac{\text { jumlah suatu jenis }(N)}{\text { Luas Total Area Plot }}$

Kerapatan Relatif $(\mathrm{KR})=\frac{\text { kerapatan suatu jenis }(K)}{\text { kerapatan seluruh jenis }} \times 100 \%$

Frekuensi $(\mathrm{F})=\frac{\text { jumlah plot suatu jenis }}{\text { jumlah seluruh plot }}$

Frekuensi Relatif $(\mathrm{FR})=\frac{\text { frekuensi suatu jenis }(F)}{\text { frekuensi seluruh jenis }} \times 100 \%$

Dominansi $(\mathrm{D})=\frac{\text { jumlah bidang dasar suatu jenis }}{\text { Luas Total Plot }}$

Dominansi Relatif $(\mathrm{DR})=\frac{\text { dominasi suatu jenis }(D)}{\text { dominansi seluruh jenis }} \times 100 \%$ 
b. Indeks Dominansi Jenis ( C )

Keterangan :

$$
\mathrm{C}=\left(\sum_{i}^{n} \frac{n i}{N}\right)^{2}
$$

$\mathrm{C}:$ Indeks dominansi jenis

ni : jumlah jenis ke-i

$\mathrm{N}$ : total seluruh jenis

c. Indeks Keanekaragaman Jenis $\left(\mathrm{H}^{\prime}\right)$

$$
\mathrm{H}^{\prime}=-\sum_{i=1}^{n} p i \ln p i
$$

Keterangan :

$\mathrm{H}^{\prime}=$ indeks keanekaragaman

$\mathrm{Pi}=\mathrm{ni} / \mathrm{N}$

$\mathrm{ni}=$ jumlah individu jenis ke-i

$\mathrm{N}=$ jumlah total individu semua jenis

\section{HASIL DAN PEMBAHASAN}

\section{a. Analisis Vegetasi}

1. Komposisi Jenis

Berdasarkan hasil wawancara dengan masyarakat sekitar, daerah ini termasuk dalam kawasan pantai yang digenangi setiap saat terjadinya air pasang rata-rata (normal high tide). Klasifikasi inilah yang mempengaruhi jenis tumbuhan yang tumbuhan pada suatu kawasan mangrove karena pasang asang surut juga berpengaruh terhadap jenis vegetasi mangrove yang tumbuh pada suatu kawasan mangrove.

Berdasarkan hasil penelitian yang telah dilakukan, ditemukan lima jenis penyusun vegetasi hutan mangrove yaitu Pidada (Sonneratia caseolaris), Tagal (Ceriops decandra), Nipah (Nypa fruticans), Lindur (Bruguiera gymnorizha), dan Bintaro (Cerbera manghas) (Tabel 1). Jenis tumbuhan mangrove tersebut dibagi berdasarkan 4 tingkatan yaitu tingkat semai, pancang, tiang dan pohon. Total seluruh jenis masing-masing strata tumbuhan mangrove yang ditemukan saat melakukan penelitian yaitu sebanyak 112 individu.

Berdasarkan Tabel 1, jenis mangrove yang paling banyak dijumpai pada tingkatan semai yaitu Cereops decandra sebanyak 46\%. Jenis mangrove pada tingkatan semai yang paling sedikit yaitu Nypa fruticans sebanyak 6\%. Pada tingkatan pancang, jenis mangrove yang paling banyak ditemukan yaitu Bruguiera gymnorizha sebanyak 75\%. Jenis mangrove pada tingkatan pancang yang paling sedikit ditemukan yaitu Sonneratia caseolaris sebanyak 25\%. Pada tingkatan tiang, jenis mangrove yang paling banyak ditemukan yaitu, jenis Sonneratia caseolaris sebanyak 69\%. Sedangkan jenis mangrove yang paling sedikit pada tingkat tiang yaitu Nypa fruticans yaitu sebanyak $8 \%$. Pada tingkatan pohon, hanya ditemukan jenis Pidada (Sonneratia caseolaris).

Tabel 1. Komposisi Jenis Tumbuhan Mangrove Berdasarkan Tingkatan yang Ditemukan di Kawasan Sungai Kuala Baru, Aceh Singkil 


\begin{tabular}{clrrrr}
\hline No. & Jenis & Semai & Pancang & Tiang & Pohon \\
\hline 1 & Pidada (Sonneratia caseolaris) & 13 & 1 & 9 & 25 \\
2 & Tagal (Cereops decandra) & 32 & & & \\
3 & Nipah (Nypa fruticans) & 4 & & 1 & \\
4 & Lindur (Bruguiera gymnorizha) & 16 & 3 & 3 & \\
5 & Bintaro (Cerbera manghas) & 5 & & & \\
\hline & Jumlah & $\mathbf{7 0}$ & $\mathbf{4}$ & $\mathbf{1 3}$ & $\mathbf{2 5}$ \\
\hline
\end{tabular}

2. Indeks Keanekaragaman Jenis $\left(\mathrm{H}^{\prime}\right)$

Dalam penelitian ini diperoleh nilai indeks keanekaragaman jenis yaitu antara 0 0,35 , nilai ini tergolong dalam $\mathrm{H}^{\prime}<2,3026$ yang berarti tingkat kestabilan komunitas yang rendah dan tingkat keanekaragamannya juga rendah. Rendahnya nilai indeks keanekaragaman disebabkan oleh kandungan bahan organik tanah yang rendah, yaitu kandungan $\mathrm{C}$-organik, $\mathrm{N}$-total, dan $\mathrm{pH}$ tanah. Komunitas jenis tumbuhan yang ada sangat sedikit dan jenis yang mendominasi juga sedikit, maka keanekaragaman jenisnya rendah. Keanekaragaman jenis yang tinggi menunjukkan suatu komunitas yang memiliki kompleksitas yang tinggi dan interaksi jenis yang terjadi juga tinggi. Jumlah jenis dan variasi jenis relatif kecil, yang akibatnya terjadi ketidakseimbangan ekosistem karena gangguan atau tekanan.

Tabel 2. Indeks Keanekaragaman Jenis

\begin{tabular}{llrrrr}
\hline No. & \multicolumn{1}{c}{ Jenis } & Semai & Pancang & Tiang & Pohon \\
\hline 1. & Pidada (Sonneratia caseolaris) & 0,312659 & 0,346574 & 0,254579 & 0 \\
2. & Tagal (Cereops decandra) & 0,357833 & - & - & - \\
3. & Nipah (Nypa fruticans) & 0,163554 & - & 0,197304 & - \\
4. & Lindur (Bruguiera gymnoriza) & 0,33735 & 0,215762 & 0,338385 & - \\
5. & Bintaro (Cerbera manghas) & 0,188504 & - & - & - \\
\hline
\end{tabular}

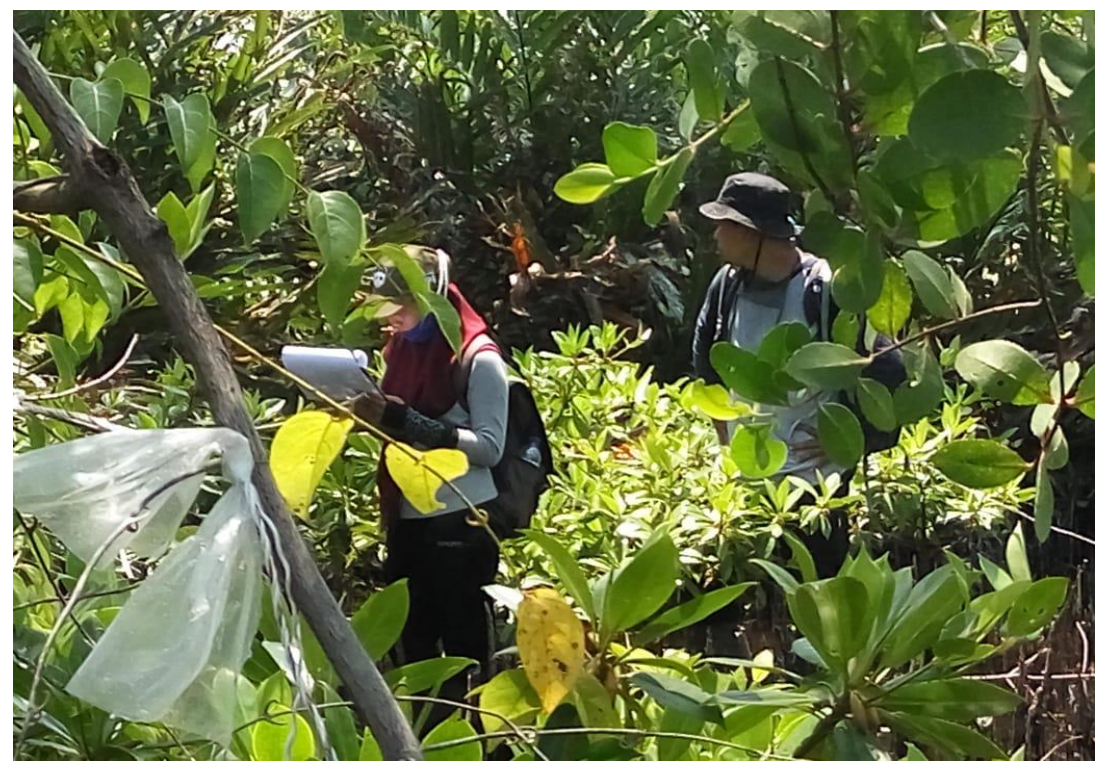

Gambar 3. Identifikasi Jenis Mangrove 
3. Kandungan Organik Tanah

Pada tabel dibawah ini menunjukkan bahwa, kandungan $\mathrm{C}$-organik pada vegetasi mangrove sebanyak 1,56\%, kandungan $\mathrm{N}$-total sebanyak 0,08\%, dan kandungan $\mathrm{pH}$ tanah yaitu 5. Kandungan $\mathrm{C}$-organik pada kawasan ini tergolong rendah dengan nilai C-organik 1,56\%. Selain C-organik, unsur hara yang lain juga berperan penting dalam ekosistem mangrove yaitu Nitrogen (N-total). Kandungan $\mathrm{N}$-total pada kawasan ini tergolong rendah dengan nilai $0,08 \%$. Nilai $\mathrm{pH}$ tanah yaitu 5 , kondisi tanah tersebut tergolong dalam kategori asam.

Tabel 3. Data Kandungan Tanah (C-organik, N-total \& pH)

\begin{tabular}{clrr}
\hline No. & & Analisis & Hasil \\
\hline 1 & C-Organik & & $1,56 \%$ \\
2 & $\mathrm{~N}$ & & $0,08 \%$ \\
3 & $\mathrm{pH}$ & 5 \\
\hline
\end{tabular}

\section{KESIMPULAN}

Nilai indeks keanekaragaman jenis $0-0,35$ tergolong dalam $\mathrm{H}^{\prime}<2,3026$ yang berarti tingkat kestabilan komunitas yang rendah dan tingkat keanekaragamannya juga rendah. Kandungan bahan organik pada kawasan ini tergolong sangat rendah dengan nilai C-organik 1,56\%. Kandungan $\mathrm{N}$-total pada kawasan ini tergolong rendah dengan nilai $0,08 \%$. Nilai $\mathrm{pH}$ pada kawasan ini adalah 5, berarti kondisi tanah tersebut tergolong asam.

\section{DAFTAR PUSTAKA}

Dave R. 2006. Mangrove Ecosystem of South, West Madagaskar : an ecological, human impact, and subsistence value assessment. Tropical Resources Bulletin 25:7-13.

Duke NC, J-O Meynecke, S Dittman, AM Ellison, K Anger, U Berger, S Cannicci, K Diele, KC Ewel, CD field, N Koedam, SY Lee, C Marchand, I Nordhaus, F Dahdouh-Guebas. 2007. AWorld without mangroves? Sciences, 317,5834, 41-42.

Giri, C., Ochieng, E. Tieszen, L., Zhu, Z., Singh, A., Loveland, T.,... Duke, N. 2011. Status and distribution of mangrove forest of the world using earth observation satellite data. Global ecology and Biogepgraphy, 20, 154-159.

Onrizal. 2005. Hutan mangrove selamatkan masyarakat pesisir Utara Nias dari tsunami. Warta Konservasi Lahan Basah 13(2): 5-7.

Primavera JH. 2005. Mangroves, fishpond, and the quest for sustainability. Sciences 310 (5745): 57-58.

Valiela, I, JL Bowen, \& JK York. 2001. Mangrove forest :one of the world's threatened major tropical environments. Biosciences 51 (10): 807-815.

Shannon, C. E., \& Weaver, W. (1949). The mathematical theory of Communication., (The University of lllinois Press: Urbana, IL, USA). 